\title{
Myocardial metabolic changes during pediatric cardiac surgery: A randomized study of $\mathbf{3}$ cardioplegic techniques
}

\section{P. Modi, FRCS \\ M.-S. Suleiman, PhD \\ B. Reeves, DPhil \\ A. Pawade, FRCS \\ A. J. Parry, FRCS \\ G. D. Angelini, FRCS \\ M. Caputo, MD}

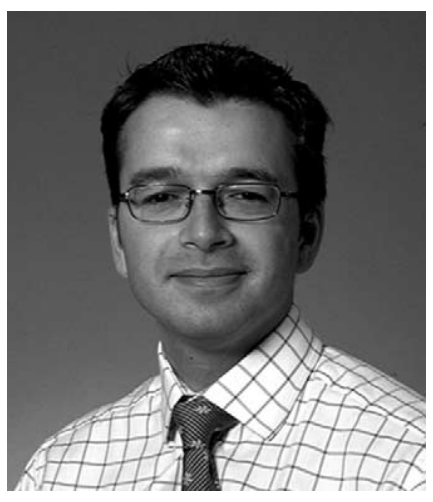

Dr Modi

See related editorial on page 11.
From Bristol Heart Institute, University of Bristol, Bristol Royal Infirmary, Bristol, United Kingdom.

Supported by the British Heart Foundation, National Heart Research Fund, and Garfield Weston Trust.

Received for publication June 23, 2003; revisions received Oct 11, 2003; accepted for publication Nov 5, 2003.

Address for reprints: M.-S. Suleiman, $\mathrm{PhD}$, Bristol Heart Institute, University of Bristol, Bristol Royal Infirmary, Bristol BS2 8HW, United Kingdom (E-mail: M.S.Suleiman@bris.ac.uk).

J Thorac Cardiovasc Surg 2004;128:67-75 $0022-5223 / \$ 30.00$

Copyright $\odot 2004$ by The American Association for Thoracic Surgery

doi:10.1016/j.jtcvs.2003.11.071
Background: Blood cardioplegia and terminal warm blood cardioplegic reperfusion ("hot shot") reduce myocardial injury and improve metabolic recovery in hypoxic but not normoxic experimental models. However, there is little evidence of a benefit of either technique in pediatric clinical practice compared with crystalloid cardioplegia.

Methods: Pediatric patients undergoing cardiac surgery were randomized to receive intermittent antegrade cold crystalloid cardioplegia, cold blood cardioplegia, or cold blood cardioplegia with a hot shot. Right ventricular biopsy specimens were collected before ischemia, at the end of ischemia, and 20 minutes after reperfusion. Cellular metabolites were analyzed. In acyanotic patients postoperative serum troponin I levels were also measured at 1, 4, 12, 24, and 48 hours.

Results: Of 103 patients recruited, 32 (22 acyanotic and 10 cyanotic), 36 (24 acyanotic and 12 cyanotic), and 35 (25 acyanotic and 10 cyanotic), respectively, were allocated to the groups receiving cold crystalloid cardioplegia, cold blood cardioplegia, and cold blood cardioplegia with a hot shot. Cyanotic patients were younger, with longer crossclamp times. There were no significant differences in clinical outcomes between cardioplegic methods. The cardioplegic method had no overall effect in terms of adenosine triphosphate, $\ln$ (adenosine triphosphate/adenosine diphosphate), or $\ln$ (glutamate) in acyanotic patients $(P=.11, P=.66$, and $P$ $=.30$, respectively). Also, there was no significant difference between groups in troponin I release. However, in cyanotic patients cold blood cardioplegia with a hot shot significantly reduced the decrease in adenosine triphosphate, $\ln$ (adenosine triphosphate/adenosine diphosphate), and glutamate observed at the end of ischemia and after reperfusion compared with the decrease seen in those receiving cold crystalloid cardioplegia $(P=.002, P=.003$, and $P=.008$, respectively), with cold blood cardioplegia representing an intermediate.

Conclusions: For cyanotic patients (younger, with longer crossclamp times), cold blood cardioplegia with a hot shot is the best method of myocardial protection. For acyanotic patients (older, with shorter crossclamp times), cardioplegic technique is not critical.

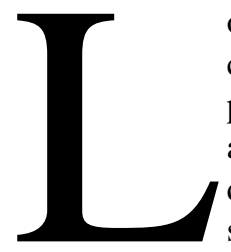

ow cardiac output after surgically induced ischemia and reperfusion continues to be a major contributor to morbidity and mortality after pediatric cardiac surgery and, in more than $50 \%$ of cases, has been attributed to inadequate myocardial protection. ${ }^{1,2}$ We have recently demonstrated that cold crystalloid cardioplegia is associated with significant ischemic stress and myocardial injury and that the extent of this is dependent on the presence of cyanosis. ${ }^{3}$ In adults blood cardioplegia has 
been shown to be superior to crystalloid cardioplegia, but because of the structural, functional, and biochemical differences between mature and immature myocardium, adult cardioprotective strategies should not be extrapolated uncritically to pediatric practice. ${ }^{4,5}$ By using a clinically relevant in vivo piglet model, blood cardioplegia has been shown to be superior to crystalloid cardioplegia in acutely hypoxic hearts, whereas both methods of cardioplegia provide protection in hearts not compromised by preoperative hypoxia. ${ }^{6}$ However, crystalloid cardioplegia, with its ease of use and less interference with visibility, is still widely used. $^{7,8}$

Postischemic recovery of function can be further optimized through careful control of the conditions of reperfusion and the composition of the reperfusate. ${ }^{9,10}$ A terminal warm blood cardioplegic reperfusate or "hot shot" allows cellular energy stores to be regenerated and channeled into repairing reversibly injured myocardium during a period of electromechanical quiescence. ${ }^{11,12}$ It has been shown experimentally to improve metabolic and short-term functional recovery and to decrease mortality in adult cardiac operations. ${ }^{13,14}$ In the immature heart this technique has been demonstrated to be effective in hypoxic piglet hearts ${ }^{15}$ and after prolonged ischemia ( 2 hours) in normoxic neonatal lamb hearts. ${ }^{16}$ However, this technique is rarely used in pediatric practice.

The aim of this study was to compare the effects of cold crystalloid cardioplegia (CC), cold blood cardioplegia (CB), and $\mathrm{CB}$ with terminal warm blood cardioplegic reperfusion ("hot shot"; $\mathrm{CB}+\mathrm{HS}$ ) on the intracellular concentrations of biochemical markers of ischemic stress in both cyanotic and acyanotic pediatric patients undergoing cardiac surgery. The postoperative release of troponin I ( TnI), a sensitive marker of myocardial injury, and several clinical outcomes were also measured.

\section{Materials and Methods}

Pediatric patients undergoing elective repair of congenital heart defects between June 2000 and December 2001 at the Royal Hospital for Children, Bristol, were prospectively randomized to receive either intermittent antegrade $\mathrm{CC}$ (St Thomas I crystalloid cardioplegia, $20 \mathrm{mmol} / \mathrm{L} \mathrm{KCl}, 16 \mathrm{mmol} / \mathrm{L} \mathrm{MgCl}_{2}, 2.2 \mathrm{mmol} / \mathrm{L}$ $\mathrm{CaCl}_{2}, 144 \mathrm{mmol} / \mathrm{L} \mathrm{NaCl}$, and $1.0 \mathrm{mmol} / \mathrm{L}$ procaine $\left.\mathrm{HCl}\right), \mathrm{CB}(4: 1$ dilution blood/St Thomas' I crystalloid cardioplegia to give the same at-patient concentrations), or $\mathrm{CB}+\mathrm{HS}$.

Simple random treatment allocations (ie, not blocked or stratified) were generated in advance of starting the study and were concealed in sequentially numbered and sealed opaque envelopes. After written informed parental consent was obtained, a patient was randomized by opening the next numbered envelope. The study was approved by the hospital ethics committee.

\section{Anesthetic and Surgical Technique}

Anesthetic technique was standardized, as reported previously. ${ }^{3}$ Cardiopulmonary bypass (CPB) was established between ascend- ing aortic and bicaval cannulae with moderate systemic hypothermia $\left(28^{\circ} \mathrm{C}-32^{\circ} \mathrm{C}\right)$. After the aorta was crossclamped, either $\mathrm{CC}$ or $\mathrm{CB}$ was infused into the aortic root at $4^{\circ} \mathrm{C}$. The induction dose was $110 \mathrm{~mL} \cdot \mathrm{m}^{-2} \cdot \mathrm{min}^{-1}$ antegradely for 4 minutes, with a maintenance dose of $110 \mathrm{~mL} \cdot \mathrm{m}^{-2} \cdot \min ^{-1}$ for 2 minutes at 20 - to 30 -minute intervals. Aortic root pressure was measured in every patient during cardioplegic delivery and was maintained between 40 and $50 \mathrm{~mm} \mathrm{Hg}$. Topical cooling with cold saline solution $\left(4^{\circ} \mathrm{C}-6^{\circ} \mathrm{C}\right)$ was used in all patients. The hot shot was identical in composition to the induction and maintenance doses and was administered at $110 \mathrm{~mL} \cdot \mathrm{m}^{-2} \cdot \min ^{-1}$ for 2 minutes at $37^{\circ} \mathrm{C}$ immediately before unclamping the aorta.

\section{Postoperative Management and Assessment of Clinical Outcome}

All patients were admitted to the pediatric intensive care unit (ICU) after the operation and managed by intensivists and pediatric cardiologists. Decisions regarding inotropic support and ventilation were based on unit protocols, hemodynamic status (eg, low mixed venous saturation and high lactic acidosis), and clinical judgment. ${ }^{3}$ Intraoperative and postoperative clinical parameters were measured. These included the durations of CPB, aortic crossclamping time, inotropic support, ventilation, ICU stay, and hospital stay.

\section{Collection of Ventricular Biopsy Specimens}

Myocardial biopsy specimens (mean weight $\pm \mathrm{SD}, 3.6 \pm 2.2 \mathrm{mg}$ ) were collected from the anterior wall of the right ventricle by using an 18-gauge, 6-cm Trucut biopsy needle (Allegiance Healthcare) immediately before crossclamping the aorta (control biopsy), just before releasing the crossclamp (ischemic biopsy), and after 20 minutes of reperfusion (reperfusion biopsy). Each specimen was immediately frozen in liquid nitrogen until processing for the analysis of adenine nucleotides, purines, lactate, and glutamate, as previously reported. ${ }^{3,14}$

\section{Measurement of Cardiac TnI}

Serum concentrations of TnI were determined before surgical intervention and at 1, 4, 12, 24, and 48 hours postoperatively by using the ACCESS Immunoassay System (Beckman Instruments). The total TnI release was calculated by using the area under the curve. Because the majority of cyanotic patients require some form of myocardial resection (to relieve obstruction of the right ventricular outflow tract) and because this is known to influence TnI release, TnI levels were only measured in acyanotic patients. ${ }^{3,17,18}$

\section{Data Collection and Statistical Analysis}

Descriptive data are summarized in tables by using medians and interquartile ranges. Clinical outcomes were compared by using $\chi^{2}$ tests and Kruskal-Wallis 1-way nonparametric analysis of variance (ANOVA). Metabolic and TnI data are presented graphically as means $\pm 95 \%$ confidence intervals. The effects of cardioplegic method, cyanosis, time (ie, control, ischemia, and reperfusion), and the interactions of these factors were investigated by means of repeated-measures ANOVA. A natural logarithmic transformation was applied to the data for all variables except adenosine triphosphate (ATP) to normalize their distributions. The baseline level (obtained from the first biopsy specimen) was entered into the 
TABLE 1. Patient characteristics and intraoperative variables

\begin{tabular}{|c|c|c|c|c|c|c|}
\hline & \multicolumn{3}{|c|}{ Acyanotic } & \multicolumn{3}{|c|}{ Cyanotic } \\
\hline & $\begin{array}{c}\text { CC } \\
(n=22)\end{array}$ & $\begin{array}{c}C B \\
(n=24)\end{array}$ & $\begin{array}{l}C B+H S \\
(n=25)\end{array}$ & $\begin{array}{c}\text { CC } \\
(n=10)\end{array}$ & $\begin{array}{c}C B \\
(n=12)\end{array}$ & $\begin{array}{l}C B+H S \\
(n=10)\end{array}$ \\
\hline \multicolumn{7}{|l|}{ Patient characteristics } \\
\hline Age (mo) & $43(4.5-69.0)$ & $41(9-98)$ & $29(6-86)$ & $13(10-23)$ & $9(7-16)$ & $14(10-16)$ \\
\hline $\operatorname{Sex}(M / F)$ & $9 / 13$ & $16 / 8$ & $14 / 11$ & $8 / 2$ & $5 / 7$ & $5 / 5$ \\
\hline Body weight $(\mathrm{kg})$ & $14.5(5.3-20.4)$ & $12.8(7.6-24.3)$ & $10.9(6.5-19.1)$ & $9.7(8.9-10.5)$ & $7.8(6.3-10.0)$ & $8.8(7.0-9.2)$ \\
\hline Preoperative hemoglobin $(\mathrm{g} / \mathrm{dL})$ & $12.5(11.4-13.9)$ & $12.6(12.0-13.7)$ & $11.9(11.3-12.8)$ & $15.0(13.2-15.8)$ & $15.0(14.6-16.4)$ & $14.0(12.7-16.3)$ \\
\hline \multicolumn{7}{|l|}{ Intraoperative variables } \\
\hline CPB time (min) & $67(46-93)$ & $71(49-86)$ & $74(46-86)$ & $110(63-141)$ & $145(125-155)$ & 133 (97-149) \\
\hline ACC time (min) & $40(27-56)$ & $40(31-56)$ & $41(31-54)$ & $59(28-78)$ & $74(43-83)$ & $71(31-87)$ \\
\hline $\mathrm{CPB}$ temperature $\left({ }^{\circ} \mathrm{C}\right)$ & $32(28-32)$ & $32(28-32)$ & $32(28-32)$ & 28 & 28 & 28 \\
\hline
\end{tabular}

Medians and interquartile ranges are shown for continuous variables.

$C C$, Cold crystalloid cardioplegia; $C B$, cold blood cardioplegia; $C B+H S$, cold blood cardioplegia + hot shot; $C P B$, cardiopulmonary bypass; $A C C$, aortic crossclamp.

ANOVA as a covariate, and ischemic and reperfusion biopsy specimens were investigated as repeated measures. The 3-way interaction of cardioplegic group, cyanosis, and time was often significant in the overall ANOVA, making the findings difficult to interpret. Separate ANOVAs for acyanotic and cyanotic subgroups were subsequently carried out to help interpretation. All data were analyzed with STATA version 7.0 software (STATA Corp).

\section{Results}

A total of 103 children were recruited into the study: 71 acyanotic and 32 cyanotic children. Twenty-two, 24, and 25 acyanotic children were randomly allocated to $\mathrm{CC}, \mathrm{CB}$, and $\mathrm{CB}+\mathrm{HS}$ cardioplegia, respectively; 10,12 , and 10 cyanotic children were randomly allocated to the corresponding groups. The characteristics of the patients and intraoperative variables are summarized in Table 1 , and the diagnoses are summarized in Table 2. Cyanotic patients tended to be younger and had longer CPB and aortic crossclamp times.

\section{Clinical Outcomes}

There were 2 postoperative deaths, both in the CB cardioplegia group: one, a 6-month-old acyanotic infant with a complete atrioventricular canal and left and right ventricular outflow tract obstruction, died 13 days postoperatively after a period of extracorporeal support; the other, a 21-monthold cyanotic child with pulmonary atresia, died on the first postoperative night after unsuccessful resuscitation from a cardiac arrest. In both cases postmortem examination revealed no evidence of myocardial infarction but was otherwise unhelpful in establishing a cause of death.

There were no significant differences in the durations or amounts of inotropic support required $(P=.57$ and $P=$ $.80)$, duration of ventilation $(P=.95)$, ICU $(P=.90)$, or hospital stay $(P=.87)$ between the cardioplegic groups (Table 3). Cyanotic patients needed significantly more postoperative inotropic and ventilatory support than acyanotic patients and spent longer in the ICU and in the hospital.
TABLE 2. Pathology

\begin{tabular}{|c|c|c|c|c|}
\hline & & $\begin{array}{c}\text { CC } \\
(n=22)\end{array}$ & $\begin{array}{c}\text { CB } \\
(n=24)\end{array}$ & $\begin{array}{l}C B+H S \\
(n=25)\end{array}$ \\
\hline \multirow[t]{5}{*}{ Acyanotic } & ASD & 6 & 6 & 6 \\
\hline & VSD & 13 & 12 & 15 \\
\hline & CAVSD & 1 & 1 & 1 \\
\hline & $\begin{array}{l}\text { Aortic-mitral } \\
\text { regurgitation }\end{array}$ & 2 & 5 & 3 \\
\hline & & $\begin{array}{c}\text { CC } \\
(n=10)\end{array}$ & $\begin{array}{c}\text { CB } \\
(n=12) \\
\end{array}$ & $\begin{array}{l}C B+H S \\
(n=10)\end{array}$ \\
\hline \multirow[t]{3}{*}{ Cyanotic } & Tetralogy of Fallot & 8 & 9 & 9 \\
\hline & Pulmonary atresia & 2 & 2 & 1 \\
\hline & DILV & 0 & 1 & 0 \\
\hline
\end{tabular}

$C C$, Cold crystalloid cardioplegia; $C B$, cold blood cardioplegia; $C B+H S$, cold blood cardioplegia + hot shot; $A S D$, atrial septal defect; $V S D$, ventricular septal defect; CAVSD, complete atrioventricular canal; DILV, double-inlet left ventricle.

\section{Metabolic Changes During Ischemia and Reperfusion}

$\boldsymbol{A T P}$. In the overall analysis of ATP levels, the main effect of the cardioplegic group was not significant in the 3 -way ANOVA $(P=.08)$, although the 3 -way interaction of cardioplegic group, cyanosis, and time was significant $(P$ $=.02$; time is control, ischemia, or reperfusion). Separate ANOVAs for acyanotic and cyanotic patients showed clearly that the effect of cardioplegic method was different in these subgroups. Cardioplegic method appeared to have no overall effect in acyanotic patients $(P=.11)$ but had a significant overall effect in cyanotic patients $(P=.002)$. This latter finding was also complicated by an interaction between cardioplegic technique and time $(P=.02)$. These findings are illustrated in Figure 1, which shows that there is a clear and parallel decrease in ATP, both during ischemia and after 20 minutes of reperfusion, in all acyanotic and cyanotic groups, except for the cyanotic patients who re- 


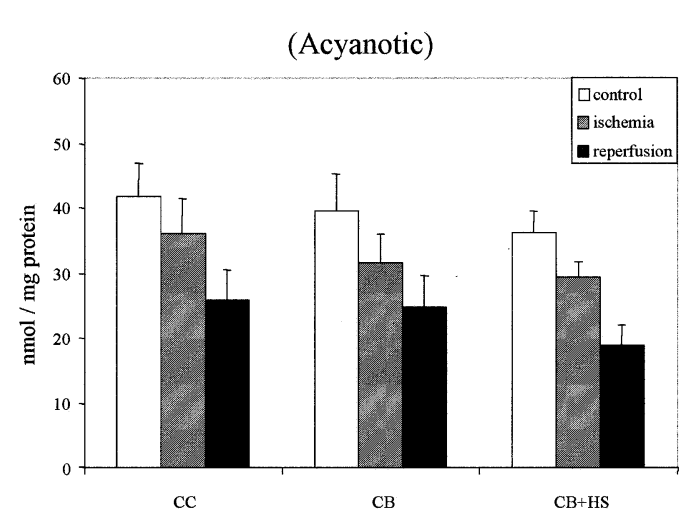

ATP

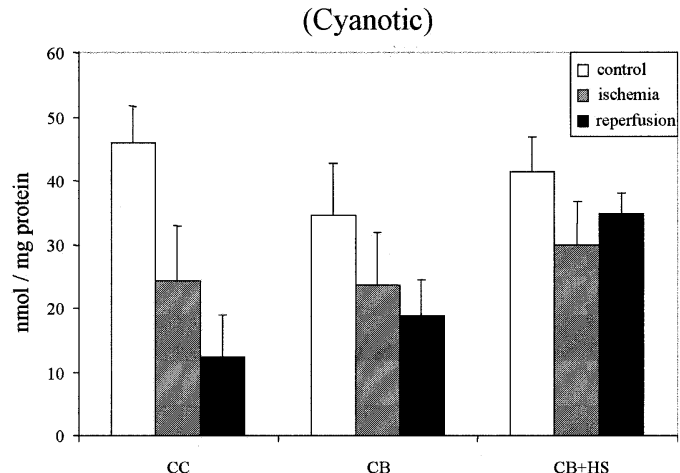

(Acyanotic)

ATP/ADP

(Cyanotic)
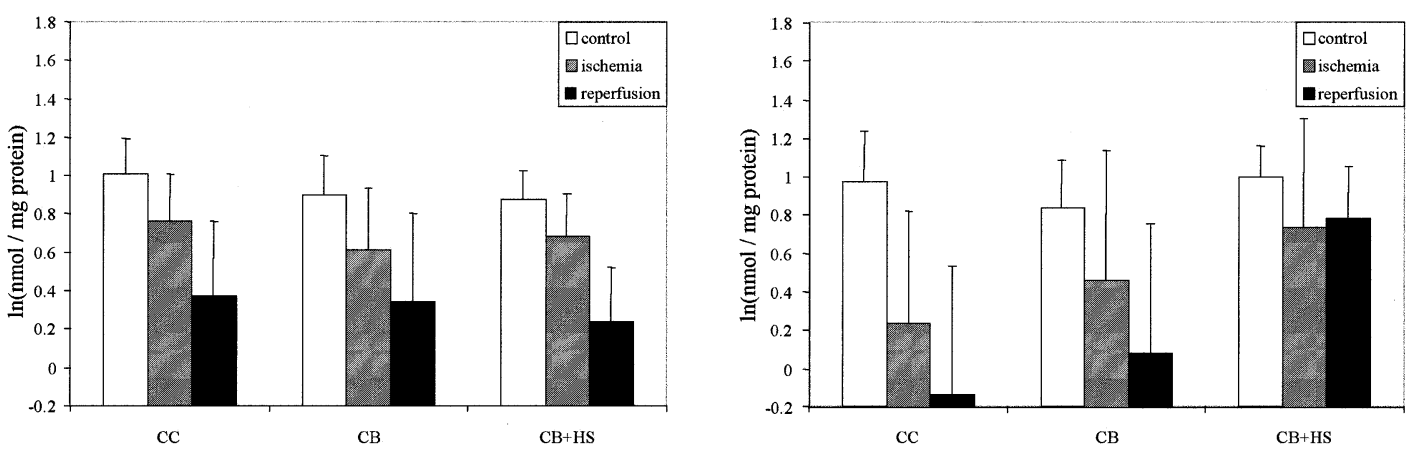

Figure 1. Bar chart showing ATP and In(ATP/ADP) before and at the end of ischemia and after 20 minutes of reperfusion in acyanotic and cyanotic patients by using the 3 cardioplegic techniques. Data are presented as means $\pm 95 \%$ confidence intervals. $C C$, Cold crystalloid; $C B$, cold blood; $C B+H S$, cold blood plus hot shot.

TABLE 3. Clinical outcomes

\begin{tabular}{|c|c|c|c|c|c|}
\hline \multicolumn{3}{|c|}{ Acyanotic } & \multicolumn{3}{|c|}{ Cyanotic } \\
\hline $\begin{array}{c}\text { CC } \\
(\mathrm{n}=22)\end{array}$ & $\begin{array}{c}\text { CB } \\
(n=24)\end{array}$ & $\begin{array}{l}C B+H S \\
(n=25)\end{array}$ & $\begin{array}{c}\text { CC } \\
(\mathrm{n}=10)\end{array}$ & $\begin{array}{c}C B \\
(n=12)\end{array}$ & $\begin{array}{l}C B+H S \\
(n=10)\end{array}$ \\
\hline
\end{tabular}

First sustained rhythm on reperfusion SR

Nodal or $1 \% / 2^{\circ}$ block

CHB

Inotropic duration (h)

Total $\mu \mathrm{g}$ dopamine $/ \mathrm{kg}\left(\times 10^{3}\right)$

Ventilation (h)

ICU stay (h)

Hospital stay (d)

$\begin{array}{cc}16 & 16 \\ 5 & 6 \\ 1 & 0 \\ 20(8-25) & 23(14-30) \\ 5.9(1.2-9.5) & 5.1(1.9-7.0) \\ 14(4-24) & 13(4-30) \\ 42(26-48) & 44(24-52) \\ 7(6-9) & 7(5-9)\end{array}$

12
8
2
$27(20-41)$
$7.2(5.4-8.7)$
$20(6-23)$
$44(28-50)$
$7(6-8)$

7
2
1
$52(48-99)$
$17.1(14.0-26.7)$
$48(26-96)$
$130(102-216)$
$12(10-16)$

9
1
0
$55(44-138)$
$16.0(12.2-36.1)$
$42(25-95)$
$104(72-161)$
$11(9-12)$

3
6
1
$62(44-123)$
$16.7(10.5-25.6$
$44(29-135)$
$96(72-159)$
$9(7-12)$

Medians and interquartile ranges are shown for continuous variables.

$C C$, Cold crystalloid cardioplegia; $C B$, cold blood cardioplegia; $C B+H S$, cold blood cardioplegia with terminal warm blood cardioplegia; $S R$, sinus rhythm; $C H B$, complete heart block; $I C U$, intensive care unit.

ceived $\mathrm{CB}+\mathrm{HS}$ cardioplegia. If anything, in this latter subgroup the level of ATP after 20 minutes of reperfusion appeared to increase.

ATP/adenosine diphosphate ratio. The findings for the ATP/adenosine diphosphate (ADP) ratio were very similar to those for ATP (Figure 2). Again, cyanotic patients who received $\mathrm{CB}+\mathrm{HS}$ appear to have benefited selectively (main effect of cardioplegic technique, $P=.003$; interaction of cardioplegic technique with time, $P=.15$ ). There was no effect of cardioplegic technique $(P=.66)$, nor was there an 
interaction of cardioplegic technique with time $(P=.28)$ among acyanotic patients. Although the interaction between cardioplegic technique and time for cyanotic patients was not statistically significant, Figure 2 shows a very similar pattern to Figure 1, with the decrease in the ATP/ADP ratio after 20 minutes of reperfusion shown by all other groups not being apparent in the cyanotic patients who received a hot shot.

Other ATP metabolites. Similar analyses were carried out for ADP, adenosine monophosphate, inosine, adenosine, and hypoxanthine. There were no significant differences among the cardioplegic groups for any of these metabolites in acyanotic or cyanotic patients. The findings for these metabolites are not described in detail here because their levels either duplicate the findings presented (eg, ADP) or represent intermediate steps in metabolism of ATP. However, ATP byproducts (eg, inosine) showed the expected pattern of accumulation during ischemia and subsequent decrease during reperfusion, with no interactions with cardioplegic technique. $P$ values for the main effects of time for inosine were .02 and .0001 for the acyanotic and cyanotic groups, respectively (Table 4).

Glutamate. The findings for glutamate levels are also very similar to those for $\ln (\mathrm{ATP} / \mathrm{ADP}$ ) and ATP (Figure 2). The cyanotic patients who received $\mathrm{CB}+\mathrm{HS}$ appear not to have experienced the continuing decrease in glutamate after 20 minutes of reperfusion that was observed in all other groups. In the separate analyses only the main effect of time was significant among acyanotic patients $(P<.0001)$, with no difference among the cardioplegic techniques. However, among cyanotic patients, the main effect of cardioplegic technique and the interaction of cardioplegic technique with time were both statistically significant $(P=.008$ and $P=$ .003 , respectively). Glutamate continued to decrease on reperfusion in the $\mathrm{CC}$ group but increased in the $\mathrm{CB}+\mathrm{HS}$ group after a hot shot. The CB group of cyanotic patients appeared to represent an intermediate result between that for the $\mathrm{CC}$ and $\mathrm{CB}+\mathrm{HS}$ groups.

Lactate. The findings for lactate levels differ from those described above for ATP, $\ln (\mathrm{ATP} / \mathrm{ADP}$ ), and glutamate (Figure 3). In the overall analysis the 3-way interaction was not significant $(P=.80)$, but in separate analyses the interaction of cardioplegic method and time approached significance for the acyanotic group $(P=.06)$, although not for the cyanotic group $(P=.21)$. The effect of time was significant for both acyanotic and cyanotic patients $(P=.03$ and $P=.0003$, respectively). Figure 4 shows that the atypical group in this case were the acyanotic patients who received CC cardioplegia; they did not show the decrease in lactate after 20 minutes of reperfusion that was observed for all other groups.

\section{TnI release}

In acyanotic patients TnI release was significantly increased by 1 hour postoperatively, peaked at 4 hours, and thereafter
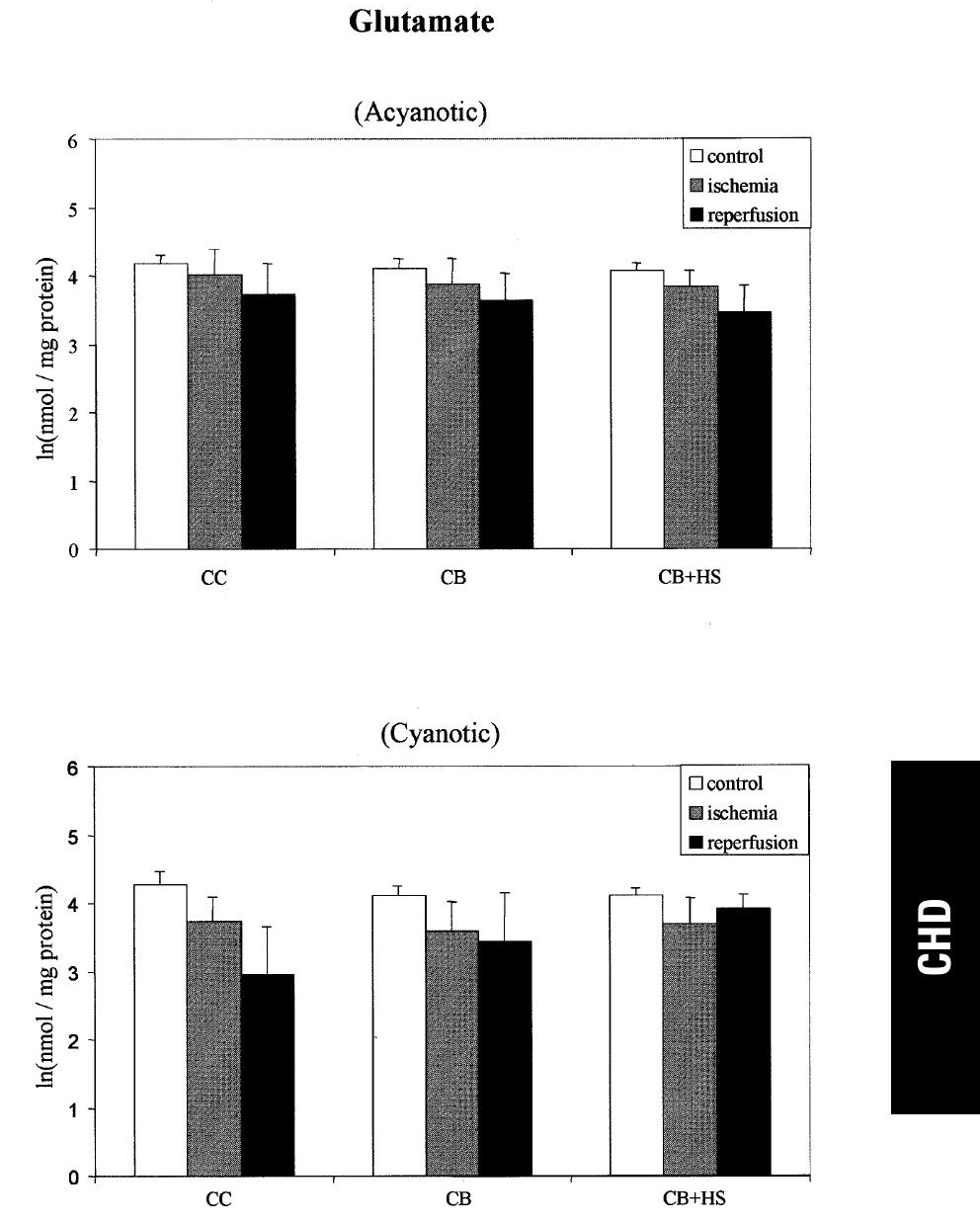

Figure 2. Bar chart showing In(glutamate) before and at the end of ischemia and after $\mathbf{2 0}$ minutes of reperfusion in acyanotic and cyanotic patients by using the 3 cardioplegic techniques. Data are presented as means $\pm 95 \%$ confidence intervals. $C C$, Cold crystalloid; $C B$, cold blood; $C B+H S$, cold blood plus hot shot.

decreased (Figure 4). However, after 48 hours, TnI levels were still increased to greater than baseline levels (data not shown on the graph because there were several missing values as a result of a lack of intravenous access). Figure 4 shows that $\mathrm{TnI}$ levels were higher at each time point in acyanotic patients who received $\mathrm{CB}+\mathrm{HS}$ cardioplegia. These apparent differences were investigated by means of a repeated-measures ANOVA of the logged TnI data, which showed that neither the overall effect of cardioplegic method nor the interaction of cardioplegic method and time reached statistical significance $(P=.13$ and $P=.12$, respectively).

\section{Discussion}

This study demonstrates that the effects of the 3 methods of cardioplegia differ in the 2 groups of pediatric patients: 
TABLE 4. Means (ATP)/geometric means* (all other metabolites) and $95 \%$ confidence intervals for cellular metabolites at baseline, at end ischemia, and after reperfusion

\begin{tabular}{|c|c|c|c|c|c|c|}
\hline & \multicolumn{3}{|c|}{ Acyanotic } & \multicolumn{3}{|c|}{ Cyanotic } \\
\hline & $\begin{array}{c}\text { CC } \\
(n=22)\end{array}$ & $\begin{array}{c}\text { CB } \\
(n=24)\end{array}$ & $\begin{array}{l}C B+H S \\
(n=25)\end{array}$ & $\begin{array}{c}\text { CC } \\
(n=10)\end{array}$ & $\begin{array}{c}\text { CB } \\
(n=12)\end{array}$ & $\begin{array}{l}C B+H S \\
(n=10)\end{array}$ \\
\hline \multicolumn{7}{|l|}{ ATP } \\
\hline Baseline & $41.7(36.7-46.8)$ & $39.5(33.7-45.2)$ & $36.3(33.0-39.5)$ & $45.9(40.1-51.8)$ & $34.6(26.5-42.7)$ & $41.4(34.6-48.3)$ \\
\hline Ischemia & $36.0(30.5-41.5)$ & $31.5(27.2-35.9)$ & $29.4(27.1-31.7)$ & $24.4(15.8-33.1)$ & $23.8(15.6-32.0)$ & $29.9(23.1-36.8)$ \\
\hline Reperfusion & $25.8(21.0-30.5)$ & $24.7(19.8-29.5)$ & $18.8(15.6-22.0)$ & $12.5(6.09-18.9)$ & $18.7(12.8-24.5)$ & $34.8(31.7-38.0)$ \\
\hline \multicolumn{7}{|l|}{ ADP } \\
\hline Baseline & $14.6(12.3-17.4)$ & $14.8(12.9-17.0)$ & $14.8(12.9-16.9)$ & $17.1(12.9-22.8)$ & 13.8 (11.7-16.4) & $15.0(12.9-17.5)$ \\
\hline Ischemia & $15.6(13.3-18.2)$ & $16.1(14.3-18.1)$ & $14.5(13.4-15.8)$ & $16.1(13.2-19.7)$ & $12.3(10.3-14.6)$ & $13.4(11.5-15.7)$ \\
\hline Reperfusion & $15.5(13.2-18.3)$ & $14.9(12.9-17.2)$ & $13.4(11.7-15.4)$ & $10.4(8.31-13.0)$ & $14.1(12.1-16.3)$ & $15.8(13.3-18.9)$ \\
\hline \multicolumn{7}{|l|}{ AMP } \\
\hline Baseline & $2.34(1.74-3.16)$ & $3.06(2.33-4.03)$ & $3.21(2.57-4.01)$ & $3.08(1.88-5.06)$ & $2.99(2.24-3.98)$ & $2.77(1.78-4.32)$ \\
\hline Ischemia & 3.31 (2.82-3.89) & $3.86(3.26-4.58)$ & $3.37(2.85-3.98)$ & $4.69(2.41-9.14)$ & $3.11(2.17-4.44)$ & $3.21(2.06-5.01)$ \\
\hline Reperfusion & $4.32(3.50-5.34)$ & $4.40(3.56-5.43)$ & $4.36(3.64-5.23)$ & $3.35(2.44-4.60)$ & $4.21(3.33-5.32)$ & $3.28(2.34-4.59)$ \\
\hline \multicolumn{7}{|l|}{ Inosine } \\
\hline Baseline & $0.95(0.69-1.30)$ & $1.03(0.76-1.39)$ & $0.94(0.74-1.18)$ & $1.04(0.70-1.54)$ & $1.44(1.08-1.91)$ & $1.10(0.72-1.66)$ \\
\hline Ischemia & $1.69(1.27-2.23)$ & $2.18(1.55-3.07)$ & $2.23(1.71-2.93)$ & $4.50(2.40-8.41)$ & $4.31(2.74-6.76)$ & $3.12(2.06-4.74)$ \\
\hline Reperfusion & $1.66(1.28-2.16)$ & $1.68(1.25-2.26)$ & $1.72(1.38-2.15)$ & $1.98(1.48-2.65)$ & $1.91(1.39-2.62)$ & $1.54(0.93-2.57)$ \\
\hline \multicolumn{7}{|l|}{ Adenosine } \\
\hline Baseline & $0.35(0.26-0.47)$ & $0.41(0.30-0.56)$ & $0.45(0.34-0.59)$ & $0.63(0.42-0.94)$ & $0.65(0.51-0.83)$ & $0.66(0.46-0.96)$ \\
\hline Ischemia & $0.49(0.40-0.61)$ & $0.61(0.47-0.80)$ & $0.66(0.54-0.81)$ & $1.32(0.83-2.09)$ & $0.83(0.57-1.21)$ & $0.87(0.60-1.26)$ \\
\hline Reperfusion & $0.52(0.40-0.67)$ & $0.61(0.47-0.81)$ & $0.58(0.46-0.73)$ & $1.02(0.65-1.61)$ & $0.69(0.56-0.84)$ & $0.57(0.33-0.96)$ \\
\hline \multicolumn{7}{|l|}{ Hypoxanthine } \\
\hline Baseline & $0.19(0.15-0.25)$ & $0.24(0.18-0.33)$ & $0.27(0.21-0.36)$ & $0.26(0.18-0.39)$ & $0.36(0.26-0.50)$ & $0.33(0.20-0.54)$ \\
\hline Ischemia & $0.55(0.45-0.68)$ & $0.59(0.42-0.83)$ & $0.71(0.54-0.94)$ & $0.83(0.51-1.35)$ & $1.01(0.66-1.55)$ & $0.77(0.47-1.28)$ \\
\hline Reperfusion & $0.63(0.47-0.85)$ & $0.51(0.40-0.64)$ & $0.57(0.45-0.73)$ & $0.30(0.19-0.48)$ & $0.49(0.35-0.70)$ & $0.67(0.43-1.02)$ \\
\hline
\end{tabular}

$C C$, Cold crystalloid cardioplegia; $C B$, cold blood cardioplegia; $C B+H S$, cold blood cardioplegia with terminal warm blood cardioplegia; ATP, adenosine triphosphate; $A D P$, adenosine diphosphate; AMP, adenosine monophosphate.

*All values are in natural units (ie, nmol/mg protein). However, geometric means (ie, exp[mean of logged values]) and $95 \%$ confidence intervals (ie, exp[mean of logged values $\pm 1.96 \mathrm{SEs}]$ ) are reported for all metabolites other than ATP because the distributions for these metabolites were positively skewed.

acyanotic (who tend to be older, with shorter crossclamp times) and cyanotic (younger, with longer crossclamp times). $\mathrm{CB}+\mathrm{HS}$ is the best method in cyanotic patients; $\mathrm{CB}$ on its own appears to be better than CC but not as good as $\mathrm{CB}+\mathrm{HS}$. In acyanotic patients the method of cardioplegia appears not to be critical in the setting of relatively brief crossclamp time ( $<45$ minutes).

\section{Limitations of the Study}

In reporting the results, we have focused on the analyses carried out separately for acyanotic and cyanotic patients rather than the overall results, despite the fact that this subgroup analysis was not written into the protocol. However, the subgroup analysis was planned soon after recruitment and started when it became evident that the groups of acyanotic and cyanotic children differed so markedly with respect to their clinical characteristics and metabolic recovery. Therefore the subgroup analysis should be considered to be a priori rather than post hoc. There was no evidence of imbalance in preoperative characteristics on the basis of the method of cardioplegia within the acyanotic and cyanotic subgroups. Therefore it is extremely unlikely that the differences in the pattern of results between methods of cardioplegia with the acyanotic and cyanotic subgroups can be explained by confounding factors.

\section{Age, Ischemic Duration, and Pathology}

The small sample size of the cyanotic group limits the power of the study for this subgroup. It also prevented an analysis of a differential effect of cardioplegic technique by age (ie, $<12$ months vs $\geq 12$ months), although because cyanotic patients are generally younger, the independent contribution of an effect of age is perhaps academic. The ischemic duration was also significantly longer in the cyanotic group: in a randomized trial it is not possible to control this because it reflects the greater surgical complexity of this group of children. Cyanosis and crossclamp time are inextricably linked, and therefore any independent effect of clamp time is perhaps academic. However, if a subgroup analysis is performed of those cyanotic patients with the shortest crossclamp times, $\mathrm{CB}+\mathrm{HS}$ is still better than $\mathrm{CB}$, which is better than $\mathrm{CC}$ (data not shown). Almost all cya- 
Lactate
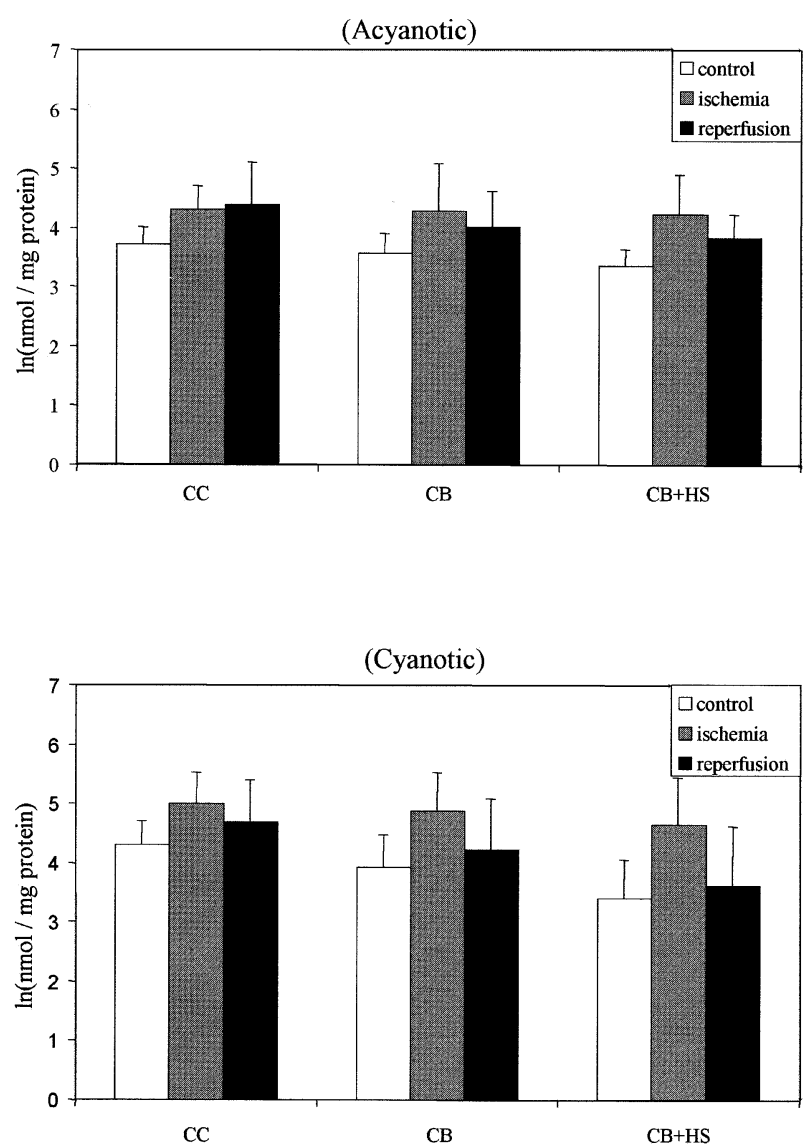

Figure 3. Bar chart showing In(lactate) before and at the end of ischemia and after $\mathbf{2 0}$ minutes of reperfusion in acyanotic and cyanotic patients by using the 3 cardioplegic techniques. Data are presented as means $\pm 95 \%$ confidence intervals. $C C$, Cold crystalloid; $C B$, cold blood; $C B+H S$, cold blood plus hot shot.

notic patients and a single pathology, tetralogy of Fallot, and therefore this is unlikely to have been a confounding factor.

\section{Interpretation of Study Findings}

We have recently shown that the use of CC in pediatric cardiac surgery is associated with significant ischemic stress and myocardial injury that is dependent on cyanosis. ${ }^{3}$ This study shows that in acyanotic patients there is little improvement in terms of metabolic data or clinical outcome if $\mathrm{CB}$ is used. In agreement with this, Fujiwara and colleagues ${ }^{19}$ found no beneficial effect of CB compared with $\mathrm{CC}$ in the normal neonatal lamb heart, although Corno and associates ${ }^{20}$ demonstrated improved recovery in the neonatal piglet heart. However, in a randomized controlled trial of 138 pediatric patients, Young and coworkers ${ }^{21}$ found no
Troponin I

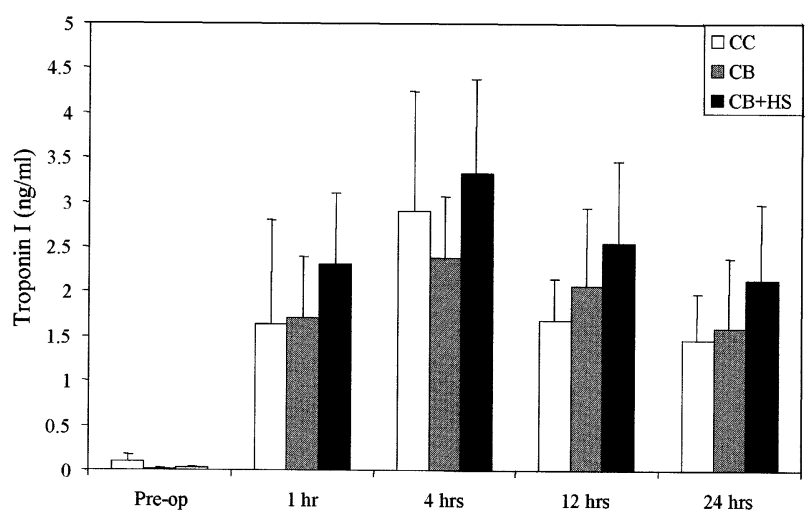

Figure 4. Bar chart showing the time-dependent release of $\mathrm{Tnl}$ in acyanotic patients. Data are presented as means $\pm 95 \%$ confidence intervals.

differences in clinical outcome between CC and CB. We also could not demonstrate any difference between $\mathrm{CB}$ and $\mathrm{CC}$ in terms of clinical outcome in a randomized controlled trial of patients undergoing repair of ventricular septal defects; however, there was less metabolic derangement with $\mathrm{CB} .^{22}$ It might be that a difference between blood and crystalloid cardioplegia would have become apparent if the ischemic (crossclamp) duration had been longer.

Despite the prevalence of hypoxia in the neonatal population, few studies have examined the question of blood versus crystalloid cardioplegia in the clinical setting. These hearts will undergo an unintended reoxygenation injury on commencement of CPB that might alter their tolerance to a subsequent period of ischemia. ${ }^{23}$ In this study we have demonstrated that preoperative cyanosis profoundly affects the protection of cardioplegic solutions on the myocardium. Blood cardioplegia partially protected the hypoxic hearts from ischemic and reoxygenation injury, whereas a severe cellular injury occurred in those protected with crystalloid cardioplegia, with a $73 \%$ reduction in preischemic mean ATP levels and a $67 \%$ reduction in the mean ATP/ADP ratio. These results, demonstrating an increased sensitivity to crystalloid cardioplegia in hypoxic hearts, parallel those obtained in acutely and chronically hypoxic experimental models $^{6,24,25}$ and in infants undergoing tetralogy repair in whom ATP levels are significantly decreased and lactate levels persistently increased during reperfusion. ${ }^{25,26}$ These findings show that crystalloid cardioplegia provides inadequate myocardial protection for hypoxic hearts.

The observation that ATP levels and the ATP/ADP ratio can be further preserved if electromechanical arrest is maintained during the first few minutes of reperfusion in the stressed (hypoxic) immature heart by means of exposure to 
a hot shot is in agreement with previous laboratory studies in neonatal piglets. ${ }^{6,15}$ However, preservation of endogenous glutamate has not been previously demonstrated. Amino acid use by transamination and substrate level phosphorylation increases the resistance of the immature heart to ischemic damage and improves functional recovery. ${ }^{27}$ Despite the metabolic advantages of warm cardioplegic reperfusion, there were no differences in clinical outcomes, indicating that the changes seen during ischemia were completely reversible. Because ATP has been shown to correlate with function, it might be that $\mathrm{CB}$ and terminal warm blood cardioplegic reperfusion incrementally ameliorate the myocardial stunning associated with crystalloid cardioplegia. $^{28}$

Only 2 previous laboratory studies have investigated warm cardioplegic reperfusion in the immature heart. ${ }^{15,16}$ Kronon and colleagues ${ }^{15}$ assessed functional and metabolic outcomes in stressed neonatal piglet hearts undergoing 60 minutes of ventilator hypoxia before 70 minutes of multidose CB arrest with and without a warm cardioplegic reperfusate. This ischemic time is comparable with that seen in our cyanotic group. They demonstrated a slight improvement in function, assessed by using pressure-volume loops, with a warm unsupplemented cardioplegic reperfusate. After 60 minutes of reperfusion, they showed an increased ATP and ATP/ADP ratio in the group receiving the cardioplegic reperfusate compared with that seen in those receiving an unmodified blood reperfusate, as we have seen. However, if aspartate and glutamate were included in the warm reperfusate, there was almost complete recovery of function and preservation of ATP. Aspartate and glutamate are thought to restore depleted Krebs cycle intermediates, which allows intact mitochondria to produce greater amounts of ATP through aerobic metabolism. ${ }^{29}$ In our study glutamate was found to be reduced to less than baseline levels, even after reperfusion, in all groups, which might suggest that glutamate enrichment, aspartate enrichment, or both of the hot shot would have improved metabolic recovery.

Cyanotic patients receiving a hot shot had higher reperfusion ATP, ATP/ADP, and glutamate levels than acyanotic patients, implying that the hot shot is advantageous only in stressed hearts (cyanotic and younger with a long ischemic interval). We do not believe that this implies that acyanotic patients are more sensitive to ischemia because this group did not have a greater decrease in metabolites during ischemia, and this also does not agree with our previous work. ${ }^{3}$ Our method of terminal cardioplegia (eg, composition and duration) might have been suboptimal, such that the benefits of electromechanical quiescence were only revealed in those hearts most likely to benefit. In contrast, Nomura and coworkers ${ }^{16}$ have reported a functional and metabolic advantage of warm blood cardioplegic reperfusion in nor- moxic neonatal lamb hearts. The reasons for these differences are due to the fact that their hearts were more stressed as a result of triple the duration of global ischemia (120 minutes), the existence of species differences in the response to ischemia and cardioplegia, ${ }^{30}$ a different age group (ie, level of maturity), and the method of terminal cardioplegia.

In summary, for cyanotic patients (who tend to be younger, with longer crossclamp times), CB supplemented with a hot shot reduces metabolic injury compared with cold crystalloid cardioplegia; $\mathrm{CB}$ on its own is better than $\mathrm{CC}$ but not as good as $\mathrm{CB}+\mathrm{HS}$. For acyanotic patients (older, with shorter crossclamp times), the method of cardioplegia is not critical when the crossclamp time is less than 45 minutes.

We thank Mark Ginty and Svitlana Korolchuk for performing the biochemical analyses, Mr D. Trivedi, and the pediatric nursing staff for their support.

\section{References}

1. Bull C, Cooper J, Stark J. Cardioplegic protection of the child's heart. J Thorac Cardiovasc Surg. 1984;88(2):287-93.

2. Hammon JW. Myocardial protection in the immature heart. Ann Thorac Surg. 1995;60(3):839-42.

3. Imura H, Caputo M, Parry A, Pawade A, Angelini GD, Suleiman M-S. Age-dependent and hypoxia-related differences in myocardial protection during pediatric open heart surgery. Circulation. 2001;103(11): 1551-6.

4. Buckberg GD, Allen BS. Myocardial protection management during adult cardiac operations. In: Baue AE, Geha AS, Hammond GL, Laks $\mathrm{H}$, Naunheim KS, editors. Glenn's thoracic and cardiovascular surgery. 6th ed. Stamford (CT): Appleton \& Lange; 1995. p. 1653-87.

5. Buckberg GD. Update on current techniques of myocardial protection. Ann Thorac Surg. 1995;60:805-14.

6. Bolling K, Kronon M, Allen BS, Wang T, Ramon S, Feinberg H. Myocardial protection in normal and hypoxically stressed neonatal hearts: the superiority of blood versus crystalloid cardioplegia. J Thorac Cardiovasc Surg. 1997;113(6):994-1003.

7. Jonas RA. Myocardial protection for neonates and infants. Thorac Cardiovasc Surg. 1998;46:288-91.

8. Bilfinger TV, Moeller JT, Kurusz M, Grimson RC, Anagnostopoulos CE. Pediatric myocardial protection in the United-States-a survey of current clinical practice. Thorac Cardiovasc Surg. 1992;40(4):214-8.

9. Follette DM, Fey K, Buckberg GD, et al. Reducing postischemic damage by temporary modification of reperfusate calcium, potassium, pH and osmolarity. J Thorac Cardiovasc Surg. 1981;82:221-38.

10. Allen BS, Okamoto F, Buckberg GD, et al. Studies of controlled reperfusion after ischemia XV. Immediate functional recovery after 6 hours of regional ischemia by careful control of conditions of reperfusion and composition of reperfusate. J Thorac Cardiovasc Surg. 1986;92:621-35.

11. Follette DM, Steed DL, Foglia RP, Fey K, Buckberg GD. Reduction of postischemic myocardial damage by maintaining arrest during initial reperfusion. Surg Forum. 1977;28:281-3.

12. Follette DM, Fey K, Steed DL, Foglia RP, Buckberg GD. Reducing reperfusion injury with hypothermic, hyperkalaemic, alkalotic blood during reoxygenation. Surg Forum. 1978;29:284-6.

13. Kirklin JW, Blackstone EH, Tchervenkov CI, Castaneda AR. Clinical outcomes after the arterial switch operation for transposition-patient, support, procedural, and institutional risk factors. Circulation. 1992; 86(5):1501-15.

14. Caputo M, Dihmis W, Bryan AJ, Suleiman M-S, Angelini GD. Warm blood hyperkalaemic reperfusion (hot shot) prevents myocardial substrate derangement in patients undergoing coronary artery bypass surgery. Eur J Cardiothorac Surg. 1998;13:559-64. 
15. Kronon MT, Allen BS, Rahman S, et al. Reducing postischemic reperfusion damage in neonates using a terminal warm substrateenriched blood cardioplegic reperfusate. Ann Thorac Surg. 2000;70: 765-70.

16. Nomura F, Forbess JM, Mayer EJ. Effects of hot shot on recovery after hypothermic ischemia in neonatal lamb heart. J Cardiovasc Surg (Torino). 2001;42(1):1-7.

17. Hirsch R, Dent CL, Wood MK, et al. Patterns and potential value of cardiac troponin I elevations after pediatric cardiac operations. Ann Thorac Surg. 1998;65(5):1394-9.

18. Modi P, Imura H, Angelini GD, et al. Pathology-related troponin I release and clinical outcome after pediatric open-heart surgery. $J$ Card Surg. 2002;18(4):295-300.

19. Fujiwara T, Heinle J, Britton L, Mayer JE Jr. Myocardial preservation in neonatal lambs: comparison of hypothermia with crystalloid and blood cardioplegia. J Thorac Cardiovasc Surg. 1991;80:703-12.

20. Corno AF, Bethencourt DM, Laks H, et al. Myocardial protection in the neonatal heart-a comparison of topical hypothermia and crystalloid and blood cardioplegic solutions. J Thorac Cardiovasc Surg. 1987;93(2):163-72.

21. Young JN, Choy IO, Silva NK, Obayashi DY, Barkan HE, Allen BS. Antegrade cold blood cardioplegia is not demonstrably advantageous over cold crystalloid cardioplegia in surgery for congenital heart disease. J Thorac Cardiovasc Surg. 1997;114:1002-9.

22. Caputo M, Modi P, Imura H, et al. Cold blood versus cold crystalloid cardioplegia for repair of ventricular septal defects in paediatric heart surgery: a randomised controlled trial. Ann Thorac Surg. 2002;74: 530-4.

23. Modi P, Imura H, Caputo M, et al. Cardiopulmonary bypass-induced myocardial reoxygenation injury in cyanotic pediatric patients. $J$ Thorac Cardiovasc Surg. 2002;124(5):1035-6.

24. Fujiwara T, Kurtts T, Anderson W, Heinle J, Mayer JE. Myocardial protection in cyanotic neonatal lambs. J Thorac Cardiovasc Surg. 1988;96:700-10.

25. Silverman NA, Kohler J, Levitsky S, Pavel DG, Fang RB, Feinberg H. Chronic hypoxemia depresses global ventricular function and predisposes to the depletion of high-energy phosphates during cardioplegic arrest-implications for surgical repair of cyanotic congenital heart defects. Ann Thorac Surg. 1984;37(4):304-8.

26. Del Nido RJ, Mickle DAG, Wilson GJ, et al. Inadequate myocardial protection with cold cardioplegic arrest during repair of tetralogy of Fallot. J Thorac Cardiovasc Surg. 1988;95(2):223-9.

27. Julia P, Young H, Buckberg GD, Kofsky E, Bugyi HI. Studies of myocardial protection in the immature heart. II. Evidence for importance of amino acid metabolism in tolerance to ischemia. $J$ Thorac Cardiovasc Surg. 1990;100:888-95.

28. Hammon JW, Graham TP, Boucek RJ, Parrish MD, Merrill WH, Bender HW. Myocardial adenosine-triphosphate content as a measure of metabolic and functional myocardial protection in children undergoing cardiac operation. Ann Thorac Surg. 1987;44(5):467-70.

29. Rosenkranz ER, Okamoto F, Buckberg GD, Robertson JM, VintenJohansen J, Bugyi H. Safety of prolonged aortic clamping with blood cardioplegia. III. Aspartate enrichment of glutamate-blood cardioplegia in energy depleted hearts after ischemia and reperfusion injury. J Thorac Cardiovasc Surg. 1986;91:428-35.

30. Baker JE, Boerboom LE, Olinger GN. Is protection of ischemic neonatal myocardium by cardioplegia species dependent? J Thorac Cardiovasc Surg. 1990;99:280-7.

\section{Availability of Journal back issues}

As a service to our subscribers, copies of back issues of The Journal of Thoracic and Cardiovascular Surgery for the preceding 5 years are maintained and are available for purchase from Elsevier Inc. until inventory is depleted. Please write to Elsevier Inc., Subscription Customer Service, 6277 Sea Harbor Dr, Orlando, FL 32877, or call $800-654-2452$ or $407-345-4000$ for information on availability of particular issues and prices. 